\title{
Economic Burden Attributable to Healthcare- Associated Infections in Tertiary Public Hospitals of Central China: A Multi-center Case-control Study
}

\author{
Peng Li \\ Henan Provincial People's Hospital \\ Yan Li \\ Henan Provincial People's Hospital \\ Youjian Zhang \\ Henan Provincial People's Hospital \\ Junzhe Bao \\ Zhengzhou University \\ Ruixia Yuan \\ First Affiliated Hospital of Zhengzhou University \\ Hongwen Lan \\ Union Hospital \\ Mingjie Sun ( $\square$ lpsxjlp@whu.edu.cn ) \\ Henan Provincial People's Hospital
}

\section{Research Article}

Keywords: healthcare-associated infection, economic burden, tertiary public hospital, Central China

Posted Date: February 15th, 2022

DOI: https://doi.org/10.21203/rs.3.rs-676716/v2

License: (9) This work is licensed under a Creative Commons Attribution 4.0 International License. Read Full License 


\section{Abstract \\ Background}

Healthcare-associated infection (HAI) is a major cause of morbidity, mortality and cost, which vary widely by region and hospital. We aimed to calculate losses attributable to HAl in central China.

\section{Methods}

We performed a three-stage random sampling and employed a 1:1 matched case-control study. The direct cost attributable to HAls was estimated and compared among different types of HAls by employing a subgroup analysis.

\section{Results}

A total of 2976 patients in 10 hospitals were enrolled, and the incidence rate of HAl (range, $0.88 \%-4.15 \%$ ) was significantly, but negatively associated with the cost per 1000 beds of its prevention (range, $\$ 24929.76-\$ 53146.41 ; r=-0.76)$. The per capita economic loss attributable to HAls was $\$ 2047.07$ (interquartile range, \$327.63-\$6429.17), mainly from the pharmaceutical cost (median, \$1044.39). The HAls, which occurred in patients with commercial medical insurance, affected the hematologic system and caused by A. baumannii, contributed most to the losses (median, $\$ 3881.55, \$ 4734.20$ and $\$ 9882.75$, respectively), and a significant correlation existed between the economic loss and age $(r=0.26)$. Furthermore, the economic losses attributable to device-associated infections and hospital-acquired multi-drug resistant bacteria were 2 to 4 times those of the controls.

\section{Conclusion}

The economic burden attributable to HAl in central China is heavy, and opportunities for easing this burden exist in several areas, including that strengthening antibiotic stewardship and practicing effective bundle of HAI prevention for patients carrying high risk factors, for example, elders or those with catheterizations in healthcare institutions, and accelerating the medical insurance payment system reform based on Diagnosis Related Groups by policy-making departments.

\section{Background}

Healthcare-Associated Infection (HAl) occurs with the founding of hospital, which is characterized by high morbidity and mortality [1]. And it is not only life-threatening and increases burden on individuals and families, but also causes huge resource wastes and economic losses for hospitals and society. The cumulative burden of HAls was about 501 disability adjusted life years per 100,000 population each year, which was higher than the total burden of all other 32 kinds of diseases included in the Burden of 
Communicable Diseases Project in Europe [2]. In the United States, 1.7 million people suffer from HAls every year, which causes an economic loss of $\$ 8.3$ billion to $\$ 11.5$ billion [3]. The impacts HAl has on patients [4], hospitals [5] and society [6] are well recognized, while most of them focused on high-income countries (HICs). What is worth mentioning, the low- and middle-income countries (LMICs) have limited medical resources but high incidences of HAls, resulting in relatively larger incidence of patient disability, mortality and additional hospitalization cost [7].

However, the burden attributable to HAls in LMICs remains poorly defined compared with that in HICs. Moreover, due to the objective factors vary, such as the demographic and sociological characteristics, medical insurance policies, economic development levels and hospital scales, the existed health economic characteristics of HAls may not have universal applicability and cannot be generalized to another hospital, country or region as a whole. Incidentally, As one of the most populous and medical resources scarce provinces in Central China, Henan Province has about 109 million population and 19 million discharged patients in 2018 [8], where there has been no research focusing on exploring the health economic characteristics of HAls because of the absence of representative data. We therefore conducted a multicenter, retrospective, standardized case-control study, to accurately estimate the current economic burden of HAls in tertiary public hospitals of Central China, and to provide data support and factual evidence for further research and policy making.

\section{Material And Methods}

\section{Patients and study design}

We adopted a three-stage random sampling method to select patients with HAls in tertiary public hospitals of Henan Province. In the first stage, based on the economic level, all 18 cities were ranked by their Gross Domestic Product (GDP) in 2018, and the first of every three cities was chosen. In the second stage, according to the total number of tertiary public hospitals of included cities and their feasibility of conducting this survey, the number of selected hospitals in each city was determined in a ratio of 3:1.

Then the hospitals in each city were ranked by the number of beds and selected by random number table method. For cities with a total number of tertiary public hospitals less than 3 , one hospital is selected by the same method. In the last stage, with a systematic sampling strategy, all patients suffered from HAl in the selected hospital between January 1 and December 312018 were ranked by their admission numbers, and the first of every seven patients was selected into the HAI group.

Then we designed the study to have 1:1 matching, with one control who did not suffer from HAl for each case. In order to reduce the confounding bias caused by undermatching or overmatching, controls were selected according to the following matching criteria: (1) the first discharge diagnoses were same, coded by the International Classification of Diseases, 10th Revision (ICD-10, Version: 2016); (2) the age-adjusted Charlson Comorbidity Index ( $\mathrm{aCCl}$ ) were equal; (3) the surgeries undergone were same, coded by the ICD Clinical Modification of 9th Revision Operations and Procedures (ICD-9-CM-3); (4) the gender were same; (5) the age gap was 5 years or less, and no more than half a year for children under 5 years old; (6) The 
inpatient departments were same; and (7) the difference of admission date was a month or less. Patients with length of stay (LOS) $\leq 2$ days were excluded, and if there was more than one patient without HAI meeting the above matching criteria, selected the one who had smallest age gap with infected patient into the control group. The HAls were diagnosed according to the Diagnostic Criteria for Nosocomial Infection, which was published by the National Health Commission of China in 2001 [9]. The study conforms to the ethical principles of the 2013 revised Declaration of Helsinki and received the Ethic Committee approval from all of the surveyed hospitals, with a waiver for patient informed consent.

\section{Data collection}

The hospitalization cost, demographic and clinical characteristics of patients were retrieved from the Hospital Information System, and the epidemiological characteristics of HAls were obtained from the Nosocomial Infections Surveillance System (NISS) of the selected hospitals. The cost of HAl prevention and control (IPC) was collected through field questionnaire surveys, which mainly comprises office expenses, labor cost of full-time and part-time staff, NISS maintenance fee, funds of activities such as training, seminar and so on. The discharge diagnoses were retrieved from the home page of electronic medical records, and the aCCl was calculated by weighting each condition to assess the aggregate burden of comorbidity [10]. The detailed calculations of hospitalization cost, IPC cost and economic loss attributable to HAl are shown in the Appendix. The average exchange rate of CNY (¥) to USD (\$) was 6.86:1, issued by The People's Bank of China from the period over which the study took place [11]. An investigator-unified training was conducted before the survey, and data validation was performed with double entry in the process of data extraction.

\section{Statistical analysis}

We used EpiData 3.1 (EpiData Association, Odense, Denmark), Excel 2010 (Microsoft Corporation, Seattle, Washington, USA) for data collection and mining, and SAS 9.4 (SAS Institute, Cary, NC, USA) for data analysis. For continuous variables (LOS and hospitalization cost) we verified the distribution types by using Kolmogorov-Smirnov test and calculating the coefficients of skewness, and then described their central tendency with mean and $95 \%$ confidence interval $(95 \% \mathrm{Cl})$ or median and interquartile range (IQR), as appropriate. The Wilcoxon signed-rank test (W test) was adopted to compare the difference of hospitalization costs between matched pairs of patients. Then a subgroup analysis was performed and the Kruskal-Wallis $\mathrm{H}$ test or Mann-Whitney $\mathrm{U}$ test were used to identify the heterogeneity of economic losses attributable to HAls among different medical insurance types, payment systems, infection sites and pathogens. In addition, the Spearman rank correlation coefficient was calculated to analyze the correlation between the prevalence of HAI and investment of its prevention, as well as that between the economic loss and patient's age. Considering of the low power of nonparametric test, the significance level (a) was set to 0.05 , not to 0.01 , to reduce the probability of false negative errors.

\section{Results}

\section{Characteristics of patients}


A total of 2976 patients in 10 hospitals (accounting for $12.99 \%$ of all tertiary public hospitals in Henan Province) were enrolled, including 7 hospitals with more than 2000 beds. No significant differences were found between the two groups with respect to gender, age, hospitals, aCCl, surgery and admission to ICU $(P>0.05 ;$ Table 1$)$. 
Table 1

Description of the included patients

\begin{tabular}{|c|c|c|c|c|}
\hline Variables & HAls & Controls & $z, t$ or $\chi^{2}$ & $P$ \\
\hline Male gender, n (\%) & $888(59.68)$ & $888(59.68)$ & 0 & 1.000 \\
\hline Age, mean in years $(95 \% \mathrm{Cl})$ & $53(51,54)$ & $52(51,54)$ & $0.370^{\mathrm{a}}$ & 0.711 \\
\hline \multicolumn{5}{|l|}{ Hospitals (anonymized), n (\%) } \\
\hline SY & $352(23.66)$ & $352(23.66)$ & \multirow[t]{10}{*}{0} & \multirow[t]{10}{*}{1.000} \\
\hline $\mathrm{HH}$ & $305(20.50)$ & $305(20.50)$ & & \\
\hline ZK & $173(11.63)$ & $173(11.63)$ & & \\
\hline ZY & 159 (10.69) & 159 (10.69) & & \\
\hline ET & $116(7.80)$ & $116(7.80)$ & & \\
\hline PD & $101(6.79)$ & $101(6.79)$ & & \\
\hline FW & $96(6.45)$ & $96(6.45)$ & & \\
\hline $\mathrm{xC}$ & $74(4.97)$ & $74(4.97)$ & & \\
\hline ZE & $60(4.03)$ & $60(4.03)$ & & \\
\hline$x X$ & $52(3.49)$ & $52(3.49)$ & & \\
\hline \multicolumn{5}{|l|}{ aCCl, n (\%) } \\
\hline 1 & $207(13.91)$ & $205(13.78)$ & \multirow[t]{7}{*}{0.372} & \multirow[t]{7}{*}{0.999} \\
\hline 2 & $231(15.52)$ & $230(15.46)$ & & \\
\hline 3 & $256(17.20)$ & $266(17.88)$ & & \\
\hline 4 & $319(21.44)$ & $323(21.71)$ & & \\
\hline 5 & $305(20.50)$ & $297(19.96)$ & & \\
\hline 6 & $122(8.20)$ & $119(8.00)$ & & \\
\hline$\geq 7$ & $48(3.23)$ & $48(3.23)$ & & \\
\hline Surgery, n (\%) & $535(35.95)$ & $535(35.95)$ & 0 & 1.000 \\
\hline Admission to ICU, n (\%) & $417(28.02)$ & $394(26.48)$ & 0.897 & 0.344 \\
\hline LOS, median in days (IQR) & $23(15,36)$ & $13(7,20)$ & $24.277^{b}$ & $<0.05$ \\
\hline
\end{tabular}




\begin{tabular}{|l|}
\hline Variables HAls Controls $\quad$ Z, t or $\chi^{2} \quad P$ \\
\hline Abbreviations: ICU, intensive care unit. \\
a The t value was calculated by using the paired t test. \\
b The standardized Z value was calculated by using W test. \\
\hline
\end{tabular}

\section{Prevalence of HAl and cost of IPC}

The overall incidence rate of HAl in the selected hospitals was 2.42\% (range, 0.88-4.15\%). And the cost of IPC per 1000 beds was $\$ 35644.24$ (range, $\$ 24929.76$ to $\$ 53146.41$ ), which was significantly, but negatively, associated with the incidence rate of $\mathrm{HAl}$ (Spearman $r=-0.76, \mathrm{P}=0.03)$..

\section{LOS and hospitalization cost}

The length of hospital environment exposure prior to the onset of HAl was 8 days (IQR, 3 to 12 days). And the LOS of HAI group was 23 days, which was 10 days (IQR, 8 to 16 days) significantly longer than that of control group (Table 1). The per patient hospitalization cost in HAl group was $\$ 2047.07$ higher than that in control group. Among hospitalization cost types, the gap of pharmaceutical cost between two groups ranked top with $\$ 1044.39$ (excess antimicrobial drug cost accounted for 59.77\%; Table 2).

Table 2

The comparison of hospitalization costs between HAl and control groups

\begin{tabular}{|c|c|c|c|c|c|c|}
\hline \multirow[t]{2}{*}{ Cost types } & \multirow{2}{*}{$\begin{array}{l}\text { No. of } \\
\text { patients }\end{array}$} & \multicolumn{2}{|c|}{ Median cost (\$) } & \multirow{2}{*}{$\begin{array}{l}\text { Median loss } \\
(\$ ; \mid \text { IQR) }\end{array}$} & \multirow[t]{2}{*}{$\mathbf{Z}$} & \multirow[t]{2}{*}{$\mathbf{P}$} \\
\hline & & HAls & Controls & & & \\
\hline Total & 2976 & 5838.11 & 2373.52 & $2047.07(327.63,6429.17)$ & 24.64 & $<0.05$ \\
\hline Pharmaceutical & 2976 & 2546.63 & 973.27 & $1044.39(98.29,3276.32)$ & 24.05 & $<0.05$ \\
\hline Antimicrobial drug & 2938 & 1179.11 & 132.38 & $624.23(73.58,2466.01)$ & 24.17 & $<0.05$ \\
\hline Operation & 1642 & 612.97 & 493.44 & $31.20(-15.96,212.46)$ & 10.24 & $<0.05$ \\
\hline Lab test & 2944 & 430.17 & 227.55 & $134.49(2.73,493.84)$ & 22.02 & $<0.05$ \\
\hline Treatment & 2970 & 382.65 & 134.84 & $134.69(14.40,513.99)$ & 22.64 & $<0.05$ \\
\hline Examination & 2880 & 356.56 & 203.79 & $101.49(-22.67,366.98)$ & 17.05 & $<0.05$ \\
\hline Blood transfusion & 1082 & 326.53 & 207.58 & $156.85(-14.80,444.31)$ & 12.05 & $<0.05$ \\
\hline Material & 2932 & 299.85 & 77.98 & $70.56(-4.40,518.67)$ & 16.93 & $<0.05$ \\
\hline Bed & 2976 & 100.27 & 50.44 & $37.27(1.04,120.52)$ & 19.82 & $<0.05$ \\
\hline Nursing care & 2976 & 72.74 & 27.11 & $26.82(2.94,136.22)$ & 22.19 & $<0.05$ \\
\hline
\end{tabular}




\section{Correlation between economic loss and age}

The hospitalization cost of HAl patients were significantly higher than that of control patients on the corresponding age levels, and there existed a significant correlation between the economic loss attributable to HAls and age (Spearman $r=0.26$; Table 3 ).

Table 3

Estimates of economic losses attributable to HAls stratified by age

\begin{tabular}{|c|c|c|c|c|c|}
\hline \multirow{2}{*}{$\begin{array}{l}\text { Age } \\
\text { (years) }\end{array}$} & \multirow{2}{*}{ No. of Patients (\%) } & \multirow{2}{*}{$\begin{array}{l}\text { Median loss } \\
(\$ ; \text { IQR) }\end{array}$} & \multicolumn{2}{|l|}{ W test } & \multirow[t]{2}{*}{ Correlation } \\
\hline & & & Z & $P$ & \\
\hline$\leq 1$ & $230(7.73)$ & $810.29(-107.27,2804.13)$ & 5.29 & $<0.05$ & \multirow{6}{*}{$\begin{array}{l}r=0.26 \\
P<0.05\end{array}$} \\
\hline $2-5$ & $134(4.50)$ & $902.46(209.86,2469.87)$ & 5.59 & $<0.05$ & \\
\hline $6-20$ & $86(2.89)$ & $1711.10(-371.04,3948.12)$ & 3.83 & $<0.05$ & \\
\hline $21-45$ & $368(12.37)$ & $1888.25(228.63,7337.86)$ & 7.85 & $<0.05$ & \\
\hline $46-65$ & $1076(36.16)$ & $1848.80(154.70,6433.48)$ & 13.85 & $<0.05$ & \\
\hline$>65$ & $1082(36.36)$ & $2872.57(810.99,8116.22)$ & 16.74 & $<0.05$ & \\
\hline
\end{tabular}

\section{Economic losses stratified by medical insurance types and payment systems}

The differences of economic losses attributable to HAls among the subgroups of different medical insurance types had marginal statistical significance $(P=0.03)$, and the economic losses in the subgroup of CMI, UEBMI and URBMI were \$1834.47, \$643.28 and \$223.49 higher than the overall median loss, respectively (Table 4). Furthermore, these losses in three different medical insurance payment systems had significant difference $(P<0.05)$, too. The economic losses in the subgroup of SD-PS and DRGs-PS were $\$ 1135.42$ and $\$ 1463.63$ lower than the overall median loss, respectively (Table 4). 
Table 4

Estimates of economic losses attributable to HAls stratified by medical insurance types and payment systems

\begin{tabular}{|c|c|c|c|c|c|c|}
\hline \multirow[t]{2}{*}{ Groups } & & \multirow{2}{*}{$\begin{array}{l}\text { No. of } \\
\text { patients } \\
(\%)\end{array}$} & \multirow{2}{*}{$\begin{array}{l}\text { Median loss } \\
(\$ ; \text { IQR) }\end{array}$} & \multicolumn{2}{|c|}{ W test } & \multirow[t]{2}{*}{$\mathrm{H}$ test } \\
\hline & & & & $\mathbf{Z}$ & $\mathbf{P}$ & \\
\hline \multirow[t]{5}{*}{$\begin{array}{l}\text { Medical insurance } \\
\text { types }\end{array}$} & $\mathrm{CMI}$ & $62(3.22)$ & $\begin{array}{l}3881.55(2979.70 \\
5345.27)^{d}\end{array}$ & 2.22 & 0.03 & \multirow{5}{*}{$\begin{array}{l}\chi^{2}= \\
10.64 \\
P=0.03\end{array}$} \\
\hline & UEBMI & $\begin{array}{l}366 \\
(19.02)\end{array}$ & $\begin{array}{l}2690.35(770.94 \\
7814.00)^{\mathrm{d}}\end{array}$ & 9.83 & $<0.05$ & \\
\hline & URBMI & $\begin{array}{l}418 \\
(21.73)\end{array}$ & $\begin{array}{l}2270.56(36.55 \\
6790.25)^{d}\end{array}$ & 9.62 & $<0.05$ & \\
\hline & NRCMI & $\begin{array}{l}980 \\
(50.94)\end{array}$ & $\begin{array}{l}\text { 1853.68 (248.06, } \\
4848.22)\end{array}$ & 14.52 & $<0.05$ & \\
\hline & Self-pay & $98(5.09)$ & $\begin{array}{l}1393.82(334.89, \\
6827.02)^{\mathrm{e}}\end{array}$ & 5.21 & $<0.05$ & \\
\hline \multirow[t]{3}{*}{ Payment systems } & HSIs-PS & $\begin{array}{l}2080 \\
(69.89)\end{array}$ & $\begin{array}{l}2857.95(437.98 \\
7047.71)^{d}\end{array}$ & 21.88 & $<0.05$ & \multirow{3}{*}{$\begin{array}{l}\chi^{2}=59.95, \\
P<0.05\end{array}$} \\
\hline & SD-PS & $\begin{array}{l}694 \\
(23.32)\end{array}$ & $\begin{array}{l}911.65(13.53 \\
3450.14)^{\mathrm{e}}\end{array}$ & 9.86 & $<0.05$ & \\
\hline & $\begin{array}{l}\text { DRGs- } \\
\text { PPS }\end{array}$ & $202(6.79)$ & $\begin{array}{l}583.44(197.63 \\
1811.49)^{\mathrm{e}}\end{array}$ & 5.22 & $<0.05$ & \\
\hline \multicolumn{7}{|c|}{$\begin{array}{l}\text { Abbreviations: CMI, commercial medical insurance; UEBMI, urban employee basic medical insurance; } \\
\text { URBMI, urban resident basic medical insurance; NRCMI, new rural cooperative medical insurance; } \\
\text { HSIs-PS, healthcare service items-payment system; SD-PS, single disease-payment system; DRGs- } \\
\text { PPS, diagnosis related groups-prospective payment system. } \\
\text { d With U test, the economic losses in these four subgroups were significantly higher than the overall } \\
\text { median loss }(P<0.05) \text {. }\end{array}$} \\
\hline \multicolumn{7}{|c|}{$\begin{array}{l}\text { e With U test, the economic losses in these three subgroups were significantly lower than the overall } \\
\text { median loss }(P<0.05) \text {. }\end{array}$} \\
\hline
\end{tabular}

\section{Economic losses stratified by infection sites}

Except the skin and soft tissue, the differences of hospitalization costs between patients with HAI in different infection sites and control group were statistically significant. And the most economic losses attributable to HAls occurred in the hematologic system (\$4734.20) and nervous system (\$4197.49). In addition, it was worth noting that the economic losses caused by VAP and CAUTI were 4.14 and 2.87 times significantly higher than those caused by the other HAls of the respiratory system and urinary system, respectively (Table 5). 
Table 5

Estimates of economic losses attributable to HAls stratified by infection sites

\begin{tabular}{|c|c|c|c|c|c|}
\hline \multirow[t]{2}{*}{ Infection sites } & \multirow{2}{*}{$\begin{array}{l}\text { No. of } \\
\text { patients }\end{array}$} & \multirow{2}{*}{$\begin{array}{l}\text { Median loss } \\
(\$ ; \text { IQR) }\end{array}$} & \multicolumn{2}{|c|}{ W or U test } & \multirow[t]{2}{*}{$\mathrm{H}$ test } \\
\hline & & & Z & $\mathrm{P}$ & \\
\hline Hematologic system & 77 & $\begin{array}{l}4734.20(1508.95 \\
11433.41)\end{array}$ & 6.49 & $<0.05$ & \multirow{11}{*}{$\begin{array}{l}x^{2}= \\
59.85 \\
P<0.05\end{array}$} \\
\hline$C L A B S I, \mathrm{n}(\%)$ & $21(27.27)$ & $\begin{array}{l}8323.47(3036.34 \\
24773.63)\end{array}$ & $1.78^{f}$ & $=0.08$ & \\
\hline Nervous system & 27 & $4197.49(1687.76,7504.14)$ & 3.82 & $<0.05$ & \\
\hline $\begin{array}{l}\text { Lower respiratory } \\
\text { tract }\end{array}$ & 871 & $2334.44(422.55,7695.91)$ & 19.17 & $<0.05$ & \\
\hline$V A P, \mathrm{n}(\%)$ & $66(7.58)$ & $\begin{array}{l}8491.32(1354.56 \\
17156.30)\end{array}$ & $3.99^{f}$ & $<0.05$ & \\
\hline Urinary system & 150 & $1933.75(110.21,5400.90)$ & 7.67 & $<0.05$ & \\
\hline CAUTI, n (\%) & $38(25.33)$ & $4687.11(748.01,9558.37)$ & $4.18^{f}$ & $<0.05$ & \\
\hline Surgical site & 72 & $1825.06(277.22,5215.32)$ & 5.12 & $<0.05$ & \\
\hline Digestive system & 81 & $1724.72(413.08,3679.93)$ & 6.03 & $<0.05$ & \\
\hline Skin and soft tissue & 18 & $1480.67(354.47,3284.53)$ & 1.59 & $=0.11$ & \\
\hline $\begin{array}{l}\text { Upper respiratory } \\
\text { tract }\end{array}$ & 157 & $825.98(-87.06,2455.20)$ & 6.71 & $<0.05$ & \\
\hline \multicolumn{6}{|c|}{$\begin{array}{l}\text { Abbreviations: CLABSI, central line-associated bloodstream infection; VAP, ventilator -associated } \\
\text { pneumonia; CAUTI, catheter-associated urinary tract infection. }\end{array}$} \\
\hline
\end{tabular}

\section{Economic losses stratified by pathogens}

A total of $568(38.17 \%)$ clinical isolates of pathogens were cultured from patients with HAl, and Escherichia coli (18.13\%) was the most frequently isolated bacterial, followed by Acinetobacter baumannii (12.68\%) and Klebsiella pneumoniae (11.27\%). The economic losses attributable to HAls caused by different pathogens had statistical significance, of which Acinetobacter baumannii was on the top list with $\$ 9882.75$. In addition, the economic losses caused by CRE, CRPa, MRSA and CRAb were 4.06, 3.64, 3.02 and 1.45 times significantly higher than those caused by CSE, CSPa, MSSA and CSAb, respectively (Table 6). 
Table 6

Estimates of economic losses attributable to HAls stratified by pathogens

\begin{tabular}{|c|c|c|c|c|c|}
\hline \multirow[t]{2}{*}{ Pathogens } & \multirow[t]{2}{*}{ No. of patients } & \multirow{2}{*}{$\begin{array}{l}\text { Median loss } \\
(\$ ; \text { IQR) }\end{array}$} & \multicolumn{2}{|c|}{ W or U test } & \multirow[t]{2}{*}{$\mathrm{H}$ test } \\
\hline & & & $\mathbf{Z}$ & $\mathbf{P}$ & \\
\hline E. coli & 103 & $2386.17(207.98,16082.23)$ & 8.39 & $<0.05$ & \multirow{13}{*}{$\begin{array}{l}X^{2}=38.21 \\
P<0.05\end{array}$} \\
\hline K. pneumoniae & 64 & $5625.70(1984.14,39346.78)$ & 7.42 & $<0.05$ & \\
\hline E. cloacae & 18 & $3724.49(491.22,8170.15)$ & 3.59 & $<0.05$ & \\
\hline$C R E, \mathrm{n}(\%)$ & $39(21.08)$ & $15921.66(6509.03,46372.36)$ & $5.72^{\mathrm{g}}$ & $<0.05$ & \\
\hline A. baumannii & 72 & $9882.75(4177.74,22594.55)$ & 7.90 & $<0.05$ & \\
\hline$C R A b, \mathrm{n}(\%)$ & $61(84.72)$ & $12436.56(5627.07,30927.52)$ & 7.299 & $<0.05$ & \\
\hline P. aeruginosa & 50 & $6384.40(2771.56,12994.86)$ & 6.51 & $<0.05$ & \\
\hline CRPa, $\mathrm{n}(\%)$ & $19(38.00)$ & $18250.11(6982.64,36036.21)$ & 4.299 & $<0.05$ & \\
\hline S. aureus & 29 & $4858.02(1215.62,13082.85)$ & 5.07 & $<0.05$ & \\
\hline MRSA, n (\%) & $11(37.93)$ & $10680.71(3926.76,23662.08)$ & $3.44^{\mathrm{g}}$ & $<0.05$ & \\
\hline Enterococcus spp & 36 & $2076.54(1090.37,13128.57)$ & 5.51 & $<0.05$ & \\
\hline C. albicans & 30 & $4190.53(837.19,8871.27)$ & 5.11 & $<0.05$ & \\
\hline S. marcescens & 12 & $2844.62(334.26,11937.43)$ & 3.47 & $<0.05$ & \\
\hline \multicolumn{6}{|c|}{$\begin{array}{l}\text { Abbreviations: CRE, carbapenem-resistant Enterobacteriaceae; CRAb, carbapenem-resistant A. } \\
\text { baumannii; CRPa, carbapenem-resistant P. aeruginosa; MRSA, Methicillin-resistant S. aureus, while S } \\
\text { is short for susceptible in CSE, CSPa, MSSA and CSAb. }\end{array}$} \\
\hline \multicolumn{6}{|c|}{$\begin{array}{l}\text { g With } U \text { test, the economic losses of HAl caused by CRE, CRAb, CRPa and MRSA were compared with } \\
\text { those caused by CSE, CSAb, CSPa and MSSA, respectively. }\end{array}$} \\
\hline
\end{tabular}

\section{Discussion}

To our knowledge, this retrospective study is the first to estimate the current economic burden and analyze the health economic characteristics of HAls in tertiary public hospitals of Central China. In this work, the estimated economic losses attributable to HAls was $\$ 2047.07$, accounting for $28.00 \%$ of per capita GDP (\$7310.79) and 63.94\% of per capita disposable income (\$3201.68) in Henan Province, 2018 [8], which is both higher than that of a retrospective survey conducted by Jia HX et al. on 68 general hospitals in China, 2015 [12] and a research did in a referral hospital of Iran, 2017 [13], but lower than the direct economic loss of HAls estimated by Li H et al. in 5 tertiary public hospitals of Hubei Province, 2016 [14] and that of a similar study made in tertiary hospitals of German, 2015 [15]. On the one hand, it is because the sample size and survey region vary among these studies. On the other hand, by assuming 
that the economic variables related to hospitalization obey the normal distribution, most of the existing studies used mean as the statistical indicator to describe the central tendency of their distributions [16, 17]. Nevertheless, the variables of hospitalization cost and economic loss in our study did not obey the normal distribution, which skewed to the right with a heavy tail, so the statistical indicator of median (lower and upper quartile) was adopted to estimate the economic loss.

In accordance with the results of current researches [17-19], the subgroup analysis shows that the economic losses caused by VAP and CAUTI were approximately 3 to 4 times higher than those caused by the other HAls of their corresponding systems, while marginal difference was found when it comes to CLABSI, probably because of the limited sample size and low power of $U$ test. We also found that the economic loss attributable to HAls came mainly from pharmaceutical cost, of which additional antimicrobial drug cost accounted for about $60 \%$. It could be explained by the fact, that antimicrobial drugs are needed to fight against infections, but along with physician's prescription comes the irrational use of antimicrobial drugs (i.e., using drug under no indication of infection, excessive dosage and overlong duration of treatment) [20], which is an independent risk factor for antimicrobial resistance [21, 22]. Meanwhile, the infection of Multiple Drug Resistant Organism (MDRO) not only causes huge economic losses, as our study and other relevant studies show [23, 24], but also increases the irrational and inappropriate use of antimicrobial drugs. Infection and antimicrobial resistance complement each other and come to a vicious circle. Therefore, the result of our study is precisely a reminder of the importance of monitoring drug prescription and controlling drug abuse for the reduction of medical burden and the prevention of MDRO infection.

In addition, this study provides the first estimate of the HAl burden on patients with different medical insurance types and payment systems, which indicated that, the HAls occurred in patients who had CMI, UEBMI or URBMI caused huge waste of healthcare resources. It was not surprising, given that the HSIs-PS is still covering most cities of Henan Province. Under this system, the excess hospitalization cost caused by HAl are mostly payed for by the medical insurance institutions and a small remaining part by the patients themselves, while the hospitals do not bear the burden basically. As the result of this study showed, the economic losses attributable to HAls in HSIs-PS were almost 5 times higher than those in DRGs-PPS, which quantifies payment criteria of different diagnosis related groups classified by the complexity of diseases and thus limits the waste of medical resources to some extent. Therefore, some developed countries strongly support the investment of HAl prevention by the medical insurance funds [25], and have established some lists of specific HAls that are referred to as "no tolerance" events, thereby reducing the reimbursements to hospitals $[26,27]$.

Our study has several limitations. Considering that the economic burden of HAl includes direct loss of prolonged stay, anti-infection treatment and readmission, as well as the indirect loss which mainly consists of the reduced working hours of family members due to hospital care and the declined labor capacity of patients themselves due to infection and even disability, the total losses attributable to HAls were underestimated in our research. Moreover, although we confirmed that there was a remarkable negative correlation between the incidence rate of $\mathrm{HAl}$ and the cost of its prevention, the cause-and-effect 
relationship between them cannot be proven by this retrospective case-control study. Further prospective studies are needed to address this issue and validate the importance of maintaining the ongoing financial investments in HAI prevention and control.

\section{Conclusion}

Based on a large, retrospective and Henan province population-based surveillance, our study demonstrates that HAls lead to a great economic loss in tertiary public hospitals of Central China, while reveals the opportunities for easing this burden exist in several areas, including that strengthening the antibiotic stewardship and practicing effective bundle of HAl prevention for patients carrying high risk factors, for example, elders or those with catheterizations in healthcare institutions, and accelerating the medical insurance payment system reform based on DRGs by policy-making departments.

\section{Abbreviations}

HAI: Healthcare-associated infection; Cl: Confidence interval; IQR: Interquartile range; HICs: High-income countries. LMICs: Low- and middle-income countries; GDP: Gross domestic product; aCCl: Age-adjusted charlson comorbidity index; LOS: Length of stay; NISS: Nosocomial infections surveillance system; IPC: Infection prevention and control; ICU: Intensive care unit; CMI: Commercial medical insurance; UEBMI: Urban employee basic medical insurance; URBMI: Urban resident basic medical insurance; NRCMI: New rural cooperative medical insurance; HSIs-PS: Healthcare service items-payment system; SD-PS: Single disease-payment system; DRGs-PPS: Diagnosis related groups-prospective payment system; CLABSI: Central line-associated bloodstream infection; VAP: Ventilator -associated pneumonia; CAUTI: Catheterassociated urinary tract infection; MDRO: Multiple drug-resistant organism; CRE: Carbapenem-resistant Enterobacteriaceae; CRAb: Carbapenem-resistant A. baumannii; CRPa: Carbapenem-resistant P. aeruginosa; MRSA: Methicillin-resistant S. aureus.

\section{Declarations}

\section{Ethics approval and Consent to Participate}

The Medical Ethics Committee of Henan Provincial People's Hospital of Zhengzhou University reviewed this study and granted ethical approval. All methods in this study were carried out in accordance with relevant guidelines and regulations, and the Medical Ethics Committee of Henan Provincial People's Hospital of Zhengzhou University granted the waiver of informed consent.

\section{Consent for publication}

Not applicable. 


\section{Availability of data and materials}

The datasets generated and/or analyzed during the current study are not publicly available due to privacy and ethical concerns, but are available from the corresponding author on reasonable request.

\section{Competing interests}

The authors declare that they have no competing interests

\section{Funding}

This work was supported by the Science and Technology Key Project of Henan Province [grant number 162102310017] and the Health Commission of Henan Province [grant number LHGJ 20190621].

\section{Acknowledgments}

We are grateful to the Centers for Nosocomial Infection Management and Quality Control of the included cities for research support, especially the infection control personnel from all included hospitals for date collecting and collating after their busy time at fighting against the COVID-19 epidemic.

\section{Author's contributions}

The couple of LY and BJZ contribute to literature search. LP, ZYJ and YRX performed data collection and statistical analysis. LP and LHW interpreted the analysis. SMJ managed its quality and gave policy advice. LP drafted the manuscript and all authors for study design and final manuscript approval.

\section{References}

1. Dennis LK, Anthony SF. Harrison's Infectious Diseases, 3/E. McGraw-Hill Medical, 2016.

2. Cassini A, Plachouras D, Eckmanns T, et al. Burden of six healthcare-associated infections on European population health: estimating incidence-based disability-adjusted life years through a population prevalence-based modelling study. PLoS Med. 2016; 13: e1002150.

3. Zimlichman E, Henderson D, Tamir O, et al. Health care-associated infections: a meta-analysis of costs and financial impact on the US health care system. JAMA Intern Med. 2013; 173:2039-46.

4. Currie K, Melone L, Stewart S, et al. Understanding the patient experience of health care-associated infection: A qualitative systematic review. Am J Infect Control. 2018; 46:936-42.

5. Kärki T, Plachouras D, Cassini A, et al. Burden of healthcare-associated infections in European acute care hospitals. Wiener Medizinische Wochenschrift. 2019; 169:3-5. 
6. Marchetti A, Rossiter R. Economic burden of healthcare-associated infection in US acute care hospitals: societal perspective. J Med Econ. 2013; 16:1399-404.

7. Bardossy AC, Zervos J, Zervos M. Preventing hospital-acquired infections in Low-income and Middleincome countries. Infect Dis Clin N Am. 2016; 30:805-18.

8. Henan Statistics Bureau. The Yearbook of Henan Statistics 2019. Beijing: China Statistics Press, 2020.

9. National Health Commission of the People's Republic of China. Diagnostic Criteria for Nosocomial Infection (in Chinese), http://www.nhc.gov.cn/wjw/gfxwj/201304/37cad8d95582456d8907ad04a5f3bd4c.shtml; 2001. [accessed 10 January 2021].

10. Charlson ME, Pompei P, Ales KL, et al. A new method of classifying prognostic comorbidity in longitudinal studies: development and validation. J Chronic Dis. 1987; 40: 373-83.

11. The People's Bank of China. The announcement of RMB central parity rate, http://www.pbc.gov.cn/zhengcehuobisi/125207/125217/125925/index.html; 2018 [accessed 21 March 2021].

12. Jia HX, Hou TY, Li WG, et al. Economic loss due to healthcare-associated infection in 68 general hospitals in China. Chinese journal of infection control. 2016; 15:637-41.

13. Soleymani F, Palangi HS, Asiabar AS, et al. Costs of hospital-acquired infection for patients hospitalized in intensive care unit of an Iranian referral hospital. Medical journal of the Islamic Republic of Iran. 2018; 32:388-93.

14. Li H, Liu X, Cui D, et al. Estimating the direct medical economic burden of health care-associated infections in public tertiary hospitals in Hubei Province, China. Asia-Pac J Public He. 2017; 29:44050.

15. Arefian H, Hagel S, Heublein S, et al. Extra length of stay and costs because of health careassociated infections at a German university hospital. Am J Infect Control. 2016; 44:160-6.

16. Nelson RE, Schweizer ML, Perencevich EN, et al. Costs and mortality associated with multidrugresistant healthcare-associated acinetobacter infections. Infect Control Hosp Epidemiol. 2016; 37:1212-8.

17. Smith DRM, Pouwels KB, Hopkins S, et al. Epidemiology and health-economic burden of urinarycatheter-associated infection in English NHS hospitals: a probabilistic modelling study. J Hosp Infect. 2019; 103:44-54.

18. Sosa HO, Matías TB, Estrada HA, et al. Incidence and costs of ventilator-associated pneumonia in the adult intensive care unit of a tertiary referral hospital in Mexico. Am J Infect Control. 2019; 47:21-5.

19. Hollenbeak CS, Schilling AL. The attributable cost of catheter-associated urinary tract infections in the United States: A systematic review. Am J Infect Control. 2018; 46: 751-7.

20. Hay SI, Rao PC, Christiane D, et al. Measuring and mapping the global burden of antimicrobial resistance. BMC Med. 2018; 16:78. 
21. Dualleh N, Chanchiri I, Skjt-Arkil H, et al. Colonization with multiresistant bacteria in acute hospital care: the association of prior antibiotic consumption as a risk factor. J Antimicrob Chemother. 2020; 75:3675-81.

22. Palacios-Baena ZR, Giannella M, Manissero D, et al. Risk factors for carbapenem-resistant Gramnegative bacterial infections: a systematic review. Clin Microbiol Infect. 2021; 27: 228-35.

23. Woolhouse M, Waugh C, Perry MR,et al. Global disease burden due to antibiotic resistance-state of the evidence. J Glob Health. 2016; 6: 010306.

24. Lee XJ, Stewardson AJ, Worth LJ, et al. Attributable Length of Stay, Mortality Risk, and Costs of Bacterial Health Care-Associated Infections in Australia: A Retrospective Case-cohort Study. Clin Infect Dis. 2021; 72: e506-14.

25. Dick AW, Perencevich EN, Pogorzelska-Maziarz M, Zwanziger J, Larson EL, Stone PW. A decade of investment in infection prevention: A cost-effectiveness analysis. Am J Infect Control. 2015; 43:4-9.

26. Wald HL, Kramer AM. Nonpayment for harms resulting from medical care: catheter-associated urinary tract infections. JAMA. 2007; 289: 2782-4.

27. Cauchi R, Hinkley K, Yondorf B. Great ideas for cutting costs: six more strategies to manage the rising costs of health care. State legislatures. 2012; 38:28-31.

\section{Appendix}

The Appendix is not available with this version 